\title{
Exploiting algae as a biomass source to produce gasoline grade hydrocarbons by high pressure pyrolysis
}

\author{
Duminda A. Gunawardena, Timothy J. Fernando, Sandun D. Fernando* \\ Biological \& Agricultural Engineering, Texas A\&M University, College Station, Texas, USA
}

Email address:

dag115@tamu.edu (D.A. Gunawardena), thimothyzkfernando@yahoo.com (T. J. Fernando). sfernando@tamu.edu (S.D. Fernando)

\section{To cite this article:}

Duminda A. Gunawardena, Timothy J. Fernando, Sandun D. Fernando. Exploiting Algae As a Biomass Source to Produce Gasoline Grade Hydrocarbons by High Pressure Pyrolysis. International Journal of Renewable and Sustainable Energy. Vol. 2, No. 2, 2013, pp. 41-45. doi: $10.11648 / j . j$ ijse.20130202.13

\begin{abstract}
The use of microalgae as a feedstock to produce hydrocarbon fuels using high pressure catalytic pyrolysis was studied. In this study, freeze dried microalgae species Nannochloropsis oculata was studied as the biomass source for pyrolysis in a micro-reactor. Algae sample was characterized by thermo gravimetric analysis (TGA) as well as FTIR analysis. To augment the hydrocarbon fraction, the effects of temperature and pressure were studied by varying the temperature from $500-800{ }^{\circ} \mathrm{C}$ in $100{ }^{\circ} \mathrm{C}$ increments and pressure $0-150 \mathrm{psi}$ in $50 \mathrm{psi}$ increments. When the sample was heated from $500-800{ }^{\circ} \mathrm{C}$ the volatiles were mainly hydrocarbons with small percentage of oxygenated and nitrogenated species. It was found that the gases evolved within $100-500^{\circ} \mathrm{C}$ were mostly oxygenated, nitrogenated and sulfided species.
\end{abstract}

Keywords: Algae; Pyrolysis; Biofuels; Nannochloropsis oculata; ZSM-5

\section{Introduction}

Algae has attracted much attention as a renewable biomass energy source due to number of reasons such as its remarkable growth rate as compared to their terrestrial counterparts, their capability of producing significant amount of lipids which can be easily translated to hydrocarbon-rich fuels, the ability to grow in non-arable land that is otherwise not suitable for any productive agricultural activity and its ability to use saline (sea) water that is vastly abundant on the surface of the earth[1-3]. Additionally, a renewable species like algae which is capable of reducing greenhouse $(\mathrm{GHG})$ gasses like $\mathrm{CO}_{2}$ is a prime elixir to avert an energy and environment crisis [3, 4].

There are various processes both chemical and biochemical that are under investigation, to convert algal biomass into fuels (fig. 1)[5, 6]. Up until yet, much of the algal conversion research has been focused on biodiesel production via isolated algal lipids [7-9]. However, the production of gasoline grade hydrocarbons via thermochemcial conversion of algae has not yet picked up much attention [10-12]. Nevertheless, the high lipid content makes algae a prime candidate for thermochemical conversion to produce hydrocarbons $[2,13]$.

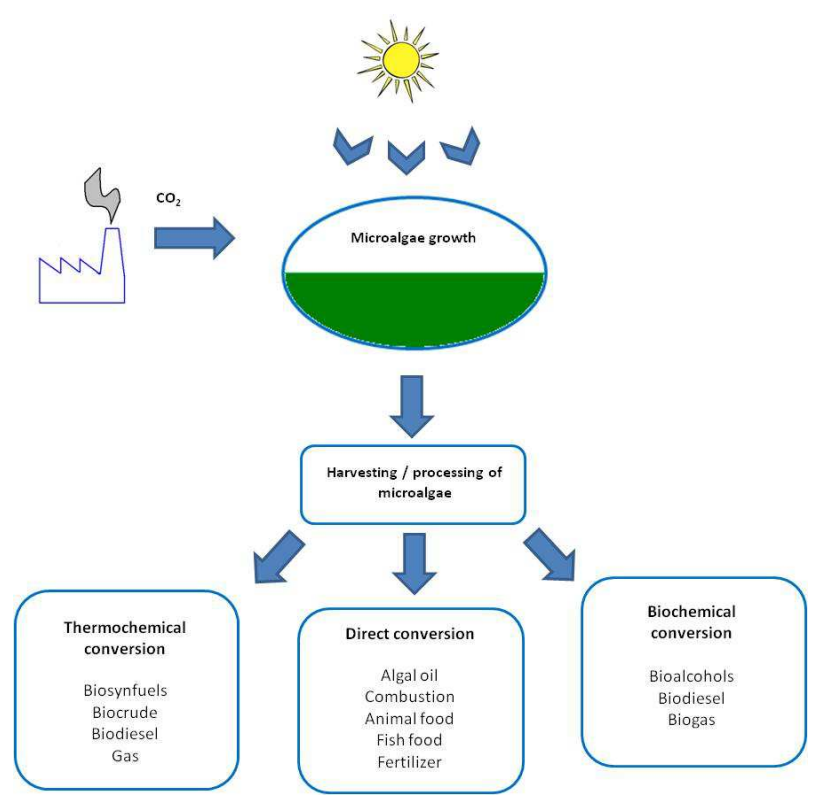

Figure 1. Main steps in algae conversion technology.(Reconstructed using information given in [3]).

For example, N. Oculata micro algae, a marine fast-growing eukaryotic unicellular flagellate with the size of about 2-4 $\mu \mathrm{m}$, were found to contain $44 \%$ long chain polyunsaturated fatty acids [14]. Accordingly, this study is 
focused on assessing the suitability of Nannochloropsis oculata micro algae as a biomass feedstock for the production of gasoline grade hydrocarbons via catalytic pyrolysis at different pressures and temperatures.

\section{Materials and Methods}

The microalgae used in this study (Nannochloropsis oculata) were lyophilized by freeze drying. Algae pyrolysis was done using high pressure CDS pyroporbe $5200 \mathrm{mi}$ cro-reactor (CDS analytical, Oxford, PA, USA) that has been retrofitted with a secondary reactor to use catalysts. An algae sample of $\sim 4 \mathrm{mg}$ was placed in a one-inch long micro quartz tube. The sample was secured using quarts wool. The quartz tube with the sample was placed in the probe's filament where the sample was heated at $700^{\circ} \mathrm{C}$. The probe's filament was fired for 20 seconds and the products were passed through the secondary reactor that was packed with a catalyst $(\sim 15 \mathrm{mg})$. Zeolite molecular sieve ZSM-5 $\left(\mathrm{SiO}_{2} / \mathrm{Al}_{2} \mathrm{O}_{3}: 30\right)$ ( Zeolyst International, Conshohocken, PA, USA) was used as the catalyst. The secondary reactor was maintained at different temperatures ranging from 500 to $800^{\circ} \mathrm{C}$ in $100^{\circ} \mathrm{C}$ increments. The products that exited the catalytic reactor were purged through a Tenax adsorbent gas trap for 3 minutes. The reactor pressure was controlled by a backpressure regulator from 0 to 150 psi guage pressure in 50 psi increments. A steady helium flow rate of $30 \mathrm{mil} / \mathrm{min}$ was maintained in the reactor. Following the adsorption run, the products were desorbed by purging the trap with gas chromatograph's (GC) carrier gas (helium) at $300^{\circ} \mathrm{C}$ and routed into the GC inlet. Desorption of the trap and initiation of the GC-mass spectrometer (MS) run was automatically synchronized. The GC-MS analysis was performed using Agilent 7890 GC coupled with Agilent 5890 MS detector (Agilent Technologies, Santa Clara, CA, USA). The column used for the MS analysis was Petrocol DH (L-100 m, ID-0.25 mm, $\mathrm{d}_{\mathrm{f}}-0.5 \mu \mathrm{m}$ ). The FTIR analysis (Thermo Scientific IS10) was done to obtain the absorbance spectra of the algae sample using diamond ATR crystal. Thermo gravimetric analysis (TGA) was done using TA instrument Q50 (TA instruments, New Castle, DE, USA) to determine the volatile fraction and the fixed carbon content of algae. The experiment was conducted as a full factorial design. Results were analyzed at $\alpha=0.05$ significance level using Design-Expert software (Stat-Ease, Inc. Minneapolis, MN, USA).

\section{Results and Discussions}

Like plant cells, algal cells are composed of a cell wall for protection against desiccation, pathogens, and predators. The cell surface consists of a lipid bi-layer which is rich in peripheral proteins. This membrane particularly consists of different regions which has its own structure as carbohydrates and lipids. The carbohydrate domain of the membrane is as a result of the side chains of the membrane bound glycolipids and glycorpotiens [15]. An IR spectroscopic study was conducted to get an idea about the membrane bound groups of $N$. Oculata . The membrane bound glycolipids and glycorpotiens have $\sim 2920 \mathrm{~cm}^{-1}$ stretching bands in the IR spectrum as shown in fig. 2.

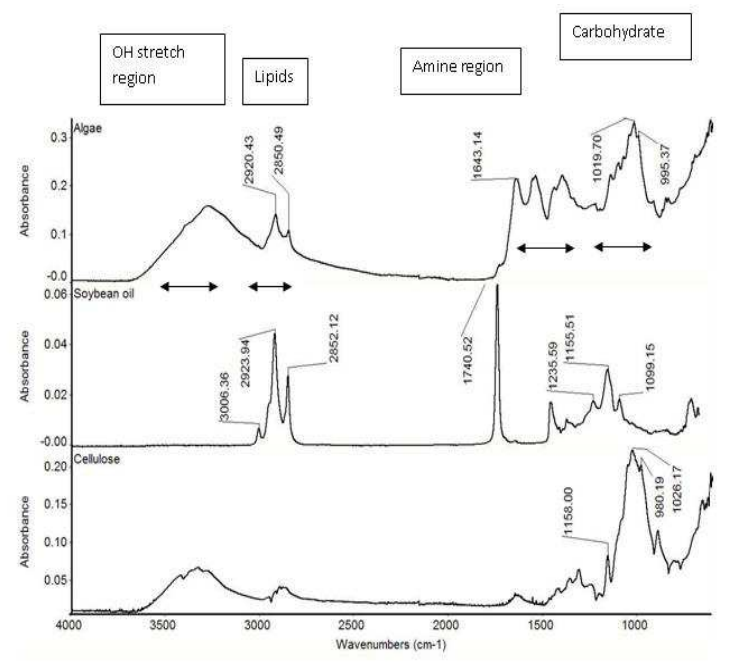

Figure 2. IR spectrum of algae and cellulose.

According to fig. 2 the carbohydrates in the membrane closely match the cellulose spectrum which was used as a reference to pyranose ring structure of carbohydrate. In addition to the carbohydrates and lipids, the interaction of IR radiation shows the presence of amines $\left(\sim 1643 \mathrm{~cm}^{-1}\right)$ and -OH groups (3000-3600 $\left.\mathrm{cm}^{-1}\right)$.

\subsection{Elemental Analysis}

Algal biomass consists of six major elements such as carbon $(\mathrm{C})$, oxygen $(\mathrm{O})$, hydrogen $(\mathrm{H})$, nitrogen $(\mathrm{N})$, sulfur (S) and phosphorus (P) and they account for nearly $90 \%$ of its total weight. The rest mainly consists of calcium $(\mathrm{Ca})$, potassium $(\mathrm{K})$, sodium $(\mathrm{Na})$, chlorine $(\mathrm{Cl})$, magnesium $(\mathrm{Mg})$, iron $(\mathrm{Fe})$, and silicon $(\mathrm{Si})$. The elemental analysis conducted on $N$. Oculata algae sample indicates the presence of $\mathrm{C}$ : $33.81 \% \mathrm{w} / \mathrm{w}, \mathrm{H}: 4.59 \% \mathrm{w} / \mathrm{w}, \mathrm{N}: 3.83 \% \mathrm{w} / \mathrm{w}, \mathrm{O}: 32.23 \% \mathrm{w} / \mathrm{w}$ and minor amounts of alkali and alkaline metals. Under pyrolysis conditions these metals are responsible for the ash content of the sample.

\subsection{Thermo Gravimetric Analysis}

A N. oculata algae sample was subjected to thermal deocomposition in a thermogravimetric (TGA) analyzer. In this study, the algal sample was heated in $\mathrm{N}_{2}$ environment until $100^{\circ} \mathrm{C}$ at a rate of $100^{\circ} \mathrm{C} / \mathrm{min}$ and kept isothermal at $100^{\circ} \mathrm{C}$ for $2 \mathrm{~min}$. Subsequently, the temperature was ramped to $800^{\circ} \mathrm{C}$ at a rate of $100^{\circ} \mathrm{C} / \mathrm{min}$ and kept isothermal at $800^{\circ} \mathrm{C}$ for $5 \mathrm{~min}$. Thereafter, the sample was combusted at a ramping rate of $100^{\circ} \mathrm{C} / \mathrm{min}$ until $1000^{\circ} \mathrm{C}$ in a gas stream of $40 \%$ $\mathrm{N}_{2}$ and $60 \% \mathrm{O}_{2}$. Here, the sample was kept isothermal at $1000^{\circ} \mathrm{C}$ for 3 mins.

According to the thermogravimetric plot which is depicted in fig. 3, five key regions can be identified. The region "A" which shows a $4.285 \%$ drop in weight is attributed to 
the evaporation of adsorbed water. When the sample was heated beyond $100^{\circ} \mathrm{C}$ up to $800^{\circ} \mathrm{C}$ there are two regions that can be distinguished. The significant difference in the change in the gradient indicates that they belong to two different reaction regimes.

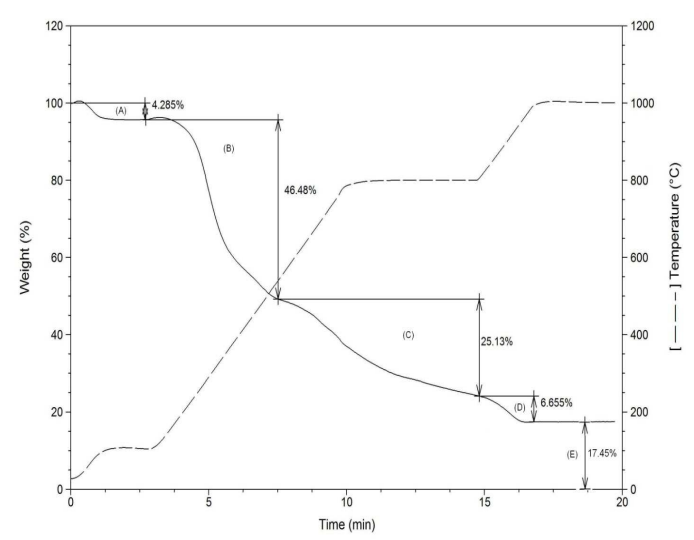

Figure 3. Thermo gravimetric analysis of the algae sample

In order to understand the reactions that may have taken place in region " $\mathrm{B}$ " and " $\mathrm{C}$ " the respective temperature regimes were simulated in the micropyrolyzer and the gaseous samples that evolved were analyzed with the GC-MS system. The area count for each product in the chromatogram was taken as a proportional representation of its concentration. The composition of the evolved gas is given in fig.4. According to the information given in fig. 4 (A), the $46.46 \%$ weight loss in region " $\mathrm{B}$ " in fig. 3 can be attributed predominantly to the loss of oxygenated, nitrogenated, and sulfided compounds. The production of hydrocarbons in region " $\mathrm{B}$ " is marginal and according to the fig. $4(\mathrm{~A})$ this is about $6.88 \%$ of the total area of the chromotogram. This observation can be related mainly to the thermal degradation of glycolipids and glycoprotiens at the temperature range of $100-500^{\circ} \mathrm{C}$.

The evolved gas composition from region " $\mathrm{C}$ " was significantly different that from region "B". According to fig. 4(B) significant drop in sulfur and nitrogen containing compounds as well as oxygenated compounds were observed. Interestingly, a dramatic increase in alkanes, alkenes and aromatic compounds which amounts to $64.37 \%$ was observed. Therefore it can be inferred that more hydrocarbon products were generated in the region " $\mathrm{C}$ " of the TGA plot. When the sample was kept at $800^{\circ} \mathrm{C}$ for $5 \mathrm{mins}$, no significant change in sample weight was observed. This is an indication of the presence of coke (free carbon) and ash in the sample.

In the subsequent run where the sample was heated at $1000^{\circ} \mathrm{C}$ in an oxygen-rich environment, this free carbon got burnt off. The region " $\mathrm{D}$ " in the fig.3 represents the weight loss due to free carbon. It indicates that there was $6.655 \%$ of free carbon in the sample. All the alkaline and alkali metals remained in the sample are depicted in region "E". According to the analysis the ash content of the algae sample was $17.45 \%$.

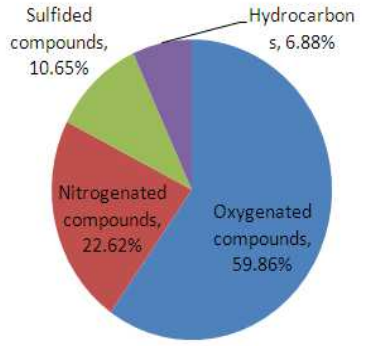

(A)

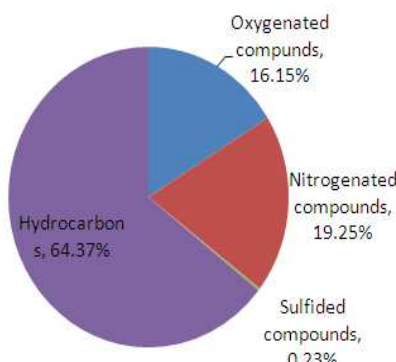

(B)
Figure 4. Composition of evolved gas in TGA at different temperature zones: (A) the temperature range $100-500^{\circ} \mathrm{C},(B)$ the temperature range $500-800^{\circ} \mathrm{C}$.

\subsection{High pressure pyrolysis}

The algae were pyrolysed in a sample tube at $800^{\circ} \mathrm{C}$ at the rate of $1000^{\circ} \mathrm{C} / \mathrm{min}$ under flash pyrolysis conditions in the micro-reactor. A high ramping rate was selected to compensate for the high temperature gradient resulting between the sample and the heating filament due to glass barrier.

It was noticed that the pyrolysis product composition obtained under flash pyrolysis condition changed significantly compared to what was observed in region ' $\mathrm{B}$ ' and " $\mathrm{C}$ " in fig.3. Further, it was also observed that the algal pyrolysis products were significantly different to glucose pyrolysis products (Fig. 5). Gulcose pyrolysis products primarily comprised of furan and low molecular weight oxygenated species as glucose is rich in oxygen where its atomic composition of $\mathrm{C}, \mathrm{H}, \mathrm{O}$ is $25 \%, 50 \%$ and $25 \%$ respectively. Due to its high lipid content algae pyrolysis products contain more hydrocarbon products.

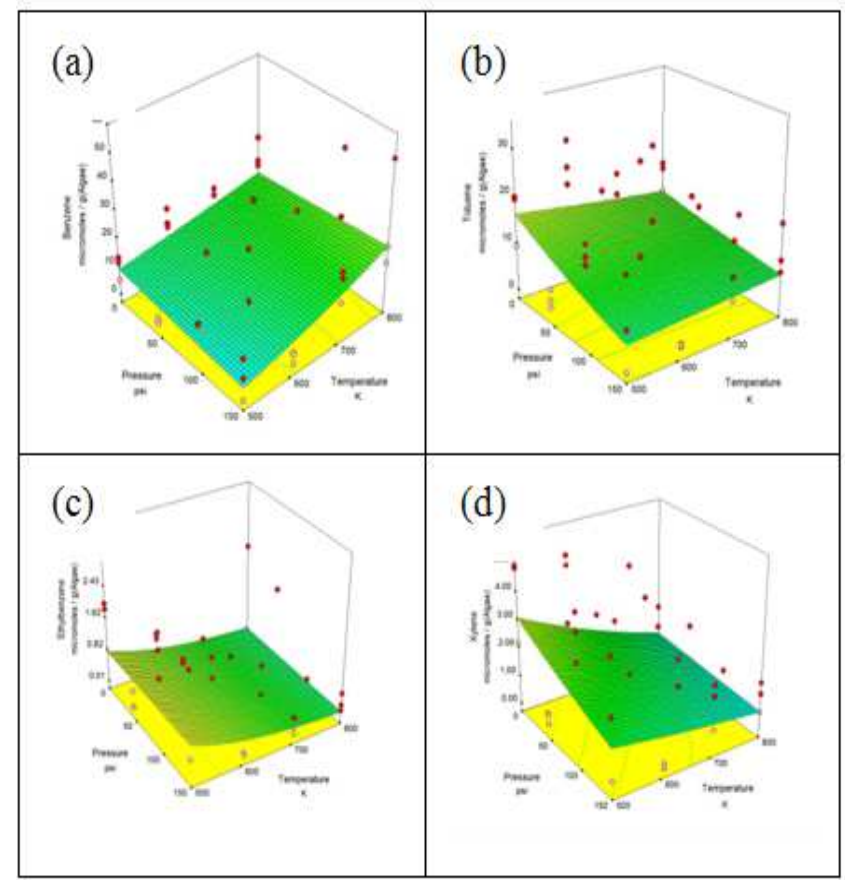

Figure 5. Aromatic yields after subjecting algae to catalytic pyrolysis at different temperatures and pressures. (a) Benzene, (b) Toluene (c) Ethylbenzene (d) Xylene 
The algal pyrolysis products primarily comprised of oxygenated, nitrogenated and sulfided products. However, catalytic pyrolysis products were primarily hydrocarbons. A catalytic conversion to hydrocarbons (HCs) would involve oxygen removal ( deoxygenation), nitrogen removal (denitrogenation) and sulfur removal (desulfurization) reactions.

In an idealized case, these three reactions can be represented as depicted in Equation 1-3. The HZSM-5 is the most widely used catalyst in these three reaction categories. The acidity of HZSM-5 which determines the proton donation ability, is critical for these reactions[16].<smiles>[R]C([R])=O</smiles>

\section{Deoxygenation}
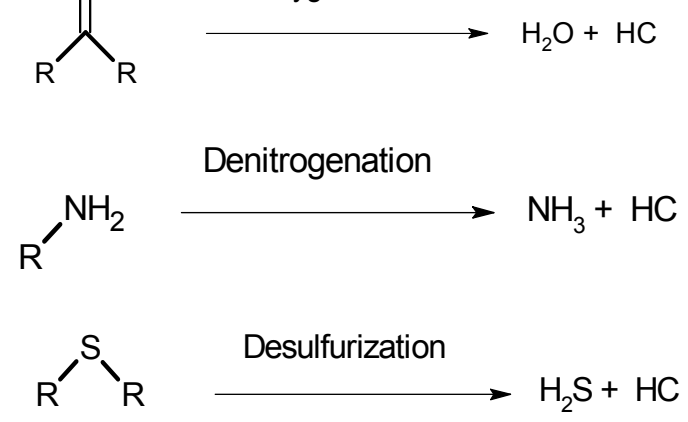

In order to augment the hydrocarbon yields from this reaction, the effect of pressure and temperature was investigated. The effect of the two variables, temperature and pressure, on overall efficacy of hydrocarbon yield is depicted in fig.5. In this study the practical limitation on the high-end values of both temperature and pressure is dictated by the strength of the reactor. Within the selected temperature and pressure range, the benzene, toluene, ethylbenzene and xylenes (BTEX) yields did not pass through a maximum or a minimum. According to the analysis, benzene production is favored at high temperature and high pressure whereas toluene, ethylbenzene and xylenes production is favored at low temperature and low pressure. At $150 \mathrm{psi}$ and $800^{\circ} \mathrm{C}$, the benzene yield was as high as $29.68(\mu \mathrm{moles} / \mathrm{gram}$ of algae). A previous study conducted on methanol deoxygenation on HZSM-5 closely matches the trend of benzene yield where it was reported that the highest benzene yield was obtained at high temperature and pressure [17].

BTEX are important components of gasoline where it accounts for a large percentage of the volume. Typically gasoline is composed of alkanes $4-8 \%(\mathrm{v} / \mathrm{v})$, alkenes $2-5 \%(\mathrm{v} / \mathrm{v})$, isoalkanes $25-40 \% \quad(\mathrm{v} / \mathrm{v}), \quad$ cycloalkanes $3-7 \%(\mathrm{v} / \mathrm{v})$, cycloalkenes $4 \%(\mathrm{v} / \mathrm{v})$ and total aromatics $20-50 \%(\mathrm{v} / \mathrm{v})[6]$. According to algae pyrolysis in the presence of HZSM-5 catalyst, it was observed that $62.8 \%$ of the total area accounts for gasoline grade hydrocarbons.

\section{Conclusions}

Microalgae species N. Oculata used in this study had $4.285 \%$ of moisture, $6.655 \%$ of carbon and $17.45 \%$ of ash. Further , $71.61 \%$ of the sample comprised of volatile components that included oxygenated, nitogenated and sulfide products. The FTIR analysis of dry algae clearly indicated the presence of surface bound lipid groups, amine groups and carbohydrate groups. Analyzing the evolved gases generated when the sample was heated from $100-500^{\circ} \mathrm{C}$ indicated a significant presence of oxygenated, nirogenated and sulfided compounds. When the sample was heated from $500-800^{\circ} \mathrm{C}$, the volatile component significantly comprised of hydrocarbons. Pyrolysis of N. Oculata in the presence of HZSM-5 clearly reduced the oxygeneated, nitrogenated and sulfided species indicating that deoxygenation, denitrogenation and desulfurization reactions occur in the presence of the HZSM-5 catalyst. Performing the reaction at high pressures and temperatures indicated that such conditions favor benzene production while low temperatures and pressures favor production of methylated aromatic products.

\section{Acknowledgment}

This work was supported by the National Science Foundation's (NSF) grant No. CBET-0965772.

\section{References}

[1] Lee, S.-J., et al., Oil Production from Five Marine Microalgae for the Production of Biodiesel. Biotechnology and $\mathrm{Bi}-$ oprocess Engineering, 2011. 16(3): p. 561-566.

[2] Babich, I.V., et al., Catalytic pyrolysis of microalgae to high-quality liquid bio-fuels. Biomass and Bioenergy, 2011. 35(7): p. 3199-3207.

[3] Demirbas, M.F., Biofuels from algae for sustainable development. Applied Energy, 2011. 88(10): p. 3473-3480.

[4] Dote, Y., et al., Recovery of liquid fuel from hydrocarbon-rich microalgae by thermochemical liquefaction. Fuel, 1994. 73(12): p. 1855-1857.

[5] Hossain, A.B.M.S. and A. Salleh, Biodiesel Fuel Production from Algae as Renewable Energy. American Journal of Biochemistry and Biotechnology 2008. 4(3): p. 250-254.

[6] Demirbas, A. and M.F. Demirbas, Algae Energy :Algae as a New Source of Biodiesel. 1 ed. Green Energy and Technology, ed. Springer. 2010: Springer.

[7] Chiu, S.-Y., et al., Lipid accumulation and CO2 utilization of Nannochloropsis oculata in response to CO2 aeration. Bioresource Technology, 2009. 100(2): p. 833-838.

[8] Yusuf, C., Biodiesel from microalgae beats bioethanol. Trends in Biotechnology, 2008. 26(3): p. 126-131.

[9] Umdu, E.S., M. Tuncer, and E. Seker, Transesterification of Nannochloropsis oculata microalga's lipid to biodiesel on Al2O3 supported $\mathrm{CaO}$ and $\mathrm{MgO}$ catalysts. Bioresource Technology, 2009. 100(11): p. 2828-2831.

[10] Pan, P., et al., The direct pyrolysis and catalytic pyrolysis of Nannochloropsis sp. residue for renewable bio-oils. Bioresource Technology, 2010. 101(12): p. 4593-4599.

[11] Duan, P. and P.E. Savage, Catalytic hydrotreatment of crude algal bio-oil in supercritical water. Applied Catalysis B: Environmental 2011. 104: p. 136-143. 
[12] Duan, P. and P.E. Savage, Catalytic treatment of crude algal bio-oil in supercritical water: optimization studies. Energy Environ. Sci., 2011. 4: p. 1447.

[13] Du, Z., et al., Microwave-assisted pyrolysis of microalgae for biofuel production. Bioresource Technology, 2011. 102(7): p. 4890-4896.

[14] Ma, X., et al., Low-temperature affected LC-PUFA conversion and associated gene transcript level in $\& l t ; i \& g t ;$ Nannochloropsis oculata\&lt;/i\&gt; CS-179. Journal of Ocean University of China (English Edition), 2011.
10(3): p. $270-274$.

[15] Barsanti, L. and P. Gualtieri, Algae: Anatomy, Biochemistry, and Biotechnology. 2006: Taylor and Fransis.

[16] Corma, A., Transformation of hydrocarbons on zeolite catalysts. Catalysis Letters, 1993. 22(1): p. 33-52.

[17] Gunawardena, D.A. and S.D. Fernando, Deoxygenation of Methanol over ZSM-5 in a High-Pressure Catalytic Pyroprobe. Chemical Engineering \& Technology, 2011. 34(2): p. 173-178. 